UDC 316.483:55

LBC 60.524.2

\title{
REGIONAL SPECIFICITY OF SOCIAL AND CRIMINAL TENSIONS IN THE RUSSIAN FEDERATION ${ }^{1}$
}

\author{
Aleksandr B. Mulik \\ Volgograd State University, Volgograd, Russian Federation
}

\begin{abstract}
Modern concepts of the environment impact on the biological and social status of human populations tend to focus on identifying persistent interracial differences in global geographical scales. Practically there is no knowledge about the mechanisms of the influence of the natural and anthropogenic environment of local territories on the behavioral characteristics of the population residing within their borders, including those causing the development of social and criminal tensions in society. The purpose of the study was to perform a comparative analysis of the severity of the standard indicators of social and criminal tensions in the regions of the Russian Federation taking into account the specific local territorial combinations of physical and geographical parameters of the human environment. At the first, theoretical stage of work, we formed a block of physics and geographical indicators of environmental quality and specified a list of indicators of social and criminal tensions in the territories endowed with a relatively typical set of discrete combinations of environmental factors characteristic of the Russian Federation. At the second stage of the survey, 1,471 people, men and women aged 18-28 years old, indigenous inhabitants of model regions of Russia were surveyed about the presence, degree and specificity of the manifestation of aggressiveness in their behavior as a factor in the development of social and criminal tensions in society. We assessed the degree of pro-sociality of respondents as well as the intensity of standard indicators of frustration, irritation and resentment. Our results obtained by the complex of studies performed indicate the possible influence on the formation of the social status of the population community, the northern latitude and eastern longitude of the place of residence, the level of the average annual temperature and longitude of the day in the winter season as well as the comfort of the human environment. Thus, systemic account of regional factors of the human environment can provide forecasting of the specifics and severity of the risk of social and criminal tensions in the society.
\end{abstract}

Key words: social tension, criminal tension, social status of the population of the Russian regions, human environment, physical and geographical parameters of the environment.

УДК 316.483:55

ББК 60.524 .2

\section{РЕГИОНАЛЬНАЯ СПЕЦИФИКА ПРОЯВЛЕНИЯ СОЦИАЛЬНОЙ И КРИМИНАЛЬНОЙ НАПРЯЖЕННОСТИ В РОССИЙСКОЙ ФЕДЕРАЦИИ ${ }^{1}$}

\author{
Александр Борисович Мулик \\ Волгоградский государственный университет, г. Волгоград, Российская Федерация
}

\begin{abstract}
Аннотация. Современные концепции воздействия окружающей среды на биологический и социальный статус человеческих популяций, как правило, ориентированы на выявление устойчивых межрасовых различий в глобальных географических масштабах. Практически отсутствуют знания о механизмах влияния природной и антропогенной среды локальных территорий на поведенческие характеристики населения проживающего в их границах, в том числе обусловливающие развитие социальной и криминальной напряженности в социуме. Целью исследования являлось выполнение сравнительного анализа выраженности стандартных показателей социальной и криминальной напряженности в регионах Российской Федерации с учетом специфики локальных территориальных сочетаний физико-географических параметров среды обитания человека. На первом, теоретическом этапе работы был сформирован блок физико-географических показате() лей качества среды и конкретизирован перечень показателей социальной и криминальной напряженности на
\end{abstract}


территориях, наделенных относительно типичным набором дискретно выраженных сочетаний факторов окружающей среды, характерных для Российской Федерации. На втором этапе работы был предпринят опрос 1471 человека, мужчин и женщин 18-28-летнего возраста, коренных жителей модельных регионов России в отношении наличия, степени и специфики проявления агрессивности в их поведении, как фактора развития социальной и криминальной напряженности в социуме. Оценивалась степень просоциальности респондентов, а также выраженность стандартных показателей фрустрации, раздражения и обиды. Результаты, полученные по комплексу выполненных исследований, свидетельствуют о возможном влиянии на становление социального статуса популяционного сообщества, северной широты и восточной долготы места жительства, уровня среднегодовой температуры и долготы дня в зимнее время года, а также комфортности среды жизнедеятельности человека. Таким образом, системный учет региональных факторов среды обитания человека может обеспечить прогнозирование специфики и выраженности риска формирования социальной и криминальной напряженности в социуме.

Ключевые слова: социальная напряженность, криминальная напряженность, социальный статус населения регионов России, среда жизнедеятельности человека, физико-географические параметры окружающей среды.

Территория Российской Федерации, характеризуясь широким спектром природногеографических и биогеохимических проявлений среды обитания, обладает уникальным разнообразием факторов формирования функционального, поведенческого и социального статуса популяционных сообществ. То влияние, которое оказывает на человека среда жизнедеятельности, неизбежно трансформируется в социальные, культурные и общественные эффекты.

В социальных исследованиях изучение природных факторов, обусловливающих социальное поведение групп и целых народов, имеет давнюю историю. Объяснение Ш.-Л. Монтескье принципов развития государств и наций природными условиями дало начало развитию идей натуралистической социологии (О. Конт, Ф. Ратцель, Г. Спенсер). Географический детерминизм Л.И. Мечникова приобрел большую популярность в конце 19 в., его работа «Цивилизация и великие исторические реки» отражает взгляд на эволюцию обществ и развитие солидарности с точки зрения освоения водных ресурсов. В 20 в. идеи Л.И. Мечникова нашли продолжение в исследованиях народов Центральной Азии Л.Н. Гумилева, доказывавшего взаимосвязь образа жизни кочевников с благоприятными климатическими условиям, низким уровнем взаимодействия друг с другом и, следовательно, с устройством государств, которые представляли скорее племенные союзы.

В психологии данная проблема разрабатывалась в рамках экологической психологии, основателем которой является Р. Баркер. Уче- ный предложил «эко-поведенческую теорию», позволявшую изучать процессы, возникающие при взаимодействии группы людей со средой. O.Н. Яницкий утверждал, что социальная среда не ограничена ближайшим окружением человека, а включает репрезентации личности «о своих «корнях», Малой Родине, ценности своего «места» (местности)». Важным феноменом в этом контексте выступает средовая идентичность, обусловленная в том числе и географическими факторами. Влияние природных факторов на поведенческие особенности личности можно проследить и в рамках этнической психологии. Наиболее выражена эта взаимосвязь через призму такого социально-психологического феномена, как национальный характер. Согласно определению А.В. Петровского, данное понятие описывает именно особенности отражения внешнего мира, обусловливающие специфику способов реагирования достаточно большой общности людей.

Отдельным, самостоятельным фактором формирования популяционных особенностей социально-психологического статуса населения является его принадлежность к разным расам, этносам, религиям, культурам. Но даже в этом вопросе необходимо признать, в качестве основополагающих элементов стабилизации этнопсихологических характеристик, общность территории проживания, совокупность природных условий, определяющих, в свою очередь, быт, характер жилья, особенности пищи, одежды, языка, традиций, самосознания, менталитета, социально-психологического статуса $[2 ; 3 ; 4 ; 5 ; 9 ; 10 ; 11]$. 
При этом современные концепции влияния природы на биологический и социальный статус человеческих популяций, как правило, ориентированы на выявление устойчивых межрасовых различий в глобальных географических масштабах. Практически отсутствуют знания о механизмах влияния природной и антропогенной среды локальных территорий на поведенческие характеристики населения, проживающего в их границах, в том числе обусловливающие развитие социальной и криминальной напряженности в социуме. Не достаточно изучена взаимосвязь факторов в системе «среда обитания - фенотип человека - социальное поведение - социальная и криминальная напряженность».

Ранее выполненные собственные исследования позволили выявить наличие устойчивых связей выраженности факторов внешней среды со спецификой проявления поведенческой и социальной активности человека. Были выделены и ранжированы регионы Российской Федерации, характеризующиеся различным уровнем природной и антропогенной нагрузки на организм человека. Наиболее высоким уровнем негативного средового давления обладают Республика Карелия, Архангельская, Иркутская и Астраханская области. Средним уровнем негативных средовых воздействий отличались Ленинградская, Са- ратовская, Ростовская, Волгоградская области и Приморский край. Низкий уровень негативного влияния внешней среды на человека характерен для Воронежской области, Краснодарского края и Республики Крым [6].

Представленные данные обеспечили возможность выполнения сравнительного анализа выраженности стандартных показателей социальной и криминальной напряженности в регионах Российской Федерации с учетом специфики локальных территориальных сочетаний физико-географических параметров среды обитания человека.

На первом, теоретическом этапе исследования, на основе картографического материала из Национального атласа России [8] был сформирован блок физико-географических показателей качества среды обитания человека в рамках территорий модельных регионов России (табл. 1).

На основании официальных данных Федеральной службы государственной статистики был конкретизирован перечень показателей социальной и криминальной напряженности в модельных регионах РФ. Выраженность проявления данных показателей отражена в таблице 2 .

На втором этапе работы был предпринят опрос коренных жителей ранее выделенных модельных регионов РФ. В опросе участвовали

Характеристика физико-географических показателей качества среды обитания

Таблийа 1 человека на территориях модельных регионов РФ

\begin{tabular}{|c|c|c|c|c|c|c|c|c|}
\hline \multirow{2}{*}{ Регион } & \multicolumn{8}{|c|}{ Показатели } \\
\hline & $\mathrm{CT}$ & $\mathrm{CP}$ & СШ & ВД & КО & ДД & $\mathrm{KC}$ & ЭС \\
\hline Республика Крым & 10,8 & 5200 & 45 & 34 & 450 & $8: 43$ & 25 & 16 \\
\hline Краснодарский край & 11,9 & 4800 & 46 & 39 & 718 & $8: 43$ & 21 & 16 \\
\hline Республика Адыгея & 11,9 & 4800 & 45 & 40 & 718 & $8: 43$ & 21 & 16 \\
\hline Ростовская область & 9,9 & 4600 & 47 & 41 & 643 & $8: 28$ & 21 & 10 \\
\hline Астраханская область & 10,5 & 5000 & 47 & 47 & 233 & $8: 28$ & 10 & 9 \\
\hline Волгоградская область & 8,1 & 4700 & 49 & 44 & 347 & $8: 10$ & 17 & 7 \\
\hline Саратовская область & 6,9 & 4400 & 51 & 47 & 476 & $7: 45$ & 21 & 11 \\
\hline Воронежская область & 6,9 & 4000 & 51 & 40 & 587 & $7: 45$ & 25 & 14 \\
\hline Республика Карелия & 3,1 & 3000 & 63 & 33 & 987 & $4: 25$ & 12 & 10 \\
\hline Архангельская область & 1,3 & 3000 & 64 & 43 & 607 & $4: 12$ & 6 & 7 \\
\hline Ленинградская область & 5,8 & 3400 & 60 & 32 & 662 & $5: 44$ & 20 & 12 \\
\hline Иркугская область & 0,9 & 4000 & 55 & 106 & 477 & $4: 50$ & 16 & 11 \\
\hline Приморский край & 4,9 & 5200 & 45 & 135 & 818 & $8: 43$ & 15 & 14 \\
\hline
\end{tabular}

Примечание. СТ - среднегодовая температура; СР - солнечная радиация; СШ - градусы северной широты; ВД - градусы восточной долготы; КО - среднегодовое количество осадков; ДД - долгота дня в декабре; КС - комфортность среды обитания; ЭС - эстетичность природной среды. 
1471 человек, мужчины и женщины 18-28-летнего возраста. Респондентам было предложено ответить на ряд вопросов определяющих наличие, степень и специфику проявления агрессивности в их поведении, как фактора развития социальной и криминальной напряженности в социуме. Оценивалась степень просоциальности опрошенных, в частности, готовность оказания безвозмездной помощи незнакомым людям, оказавшимся в трудной жизненной ситуации [7]. Кроме этого, у всех респондентов были оценены стандартные показатели фруст- рации, раздражения и обиды, отражающие текущее состояние психоэмоционального напряжения человека [1]. Полученные результаты представлены в таблице 3.

Третий, аналитический этап работы был посвящен комплексному изучению связей физикогеографических показателей качества среды обитания с отдельными показателями социальной и криминальной напряженности, а такжеличностными проявлениями социально-психологической напряженности у населения модельных регионов Российской Федерации. Для оценки на-

Таблица 2

Выраженность показателей социальной и криминальной напряженности в модельных регионах РФ

\begin{tabular}{|l|r|r|r|r|r|r|r|}
\hline \multirow{2}{*}{\multicolumn{1}{|c}{ Регион }} & \multicolumn{9}{|c|}{ Показатели } \\
\cline { 2 - 9 } & \multicolumn{1}{|c|}{ ИВ } & \multicolumn{1}{c|}{ АД } & \multicolumn{1}{c|}{ ИА } & \multicolumn{1}{c|}{ КР } & \multicolumn{1}{c|}{ СС } & \multicolumn{1}{c|}{ СУ } \\
\hline Республика Крым & 1010,9 & 20,6 & 113,0 & 4,7 & 0,09 & 23,9 & 0,04 \\
\hline Краснодарский край & 269,2 & 17,9 & 85,5 & 4,6 & 0,08 & 24,8 & 0,03 \\
\hline Республика Адыгея & 136,2 & 19,2 & 203,5 & 3,6 & 0,01 & 91,5 & 0,03 \\
\hline Ростовская область & 199,4 & 13,9 & 69,5 & 4,8 & 0,04 & 29,4 & 0,02 \\
\hline Астраханская область & 88,2 & 14,6 & 151,5 & 5,2 & 0,002 & 27,5 & 0,01 \\
\hline Волгоградская область & 421,8 & 43,5 & 85,5 & 4,1 & 0,06 & 30,8 & 0,03 \\
\hline Саратовская область & 613,5 & 26,0 & 137,5 & 4,2 & 0,13 & 25,0 & 0,04 \\
\hline Воронежская область & 68,8 & 26,5 & 167,0 & 4,1 & 0,10 & 31,8 & 0,02 \\
\hline Республика Карелия & 240,7 & 38,3 & 256,0 & 5,2 & 0,12 & 37,4 & 0,06 \\
\hline Архангельская область & 76,2 & 46,1 & 240,0 & 5,8 & 0,22 & 38,1 & 0,09 \\
\hline Ленинградская область & 1305,8 & 34,7 & 62,5 & 4,1 & 0,12 & 36,0 & 0,06 \\
\hline Иркутская область & 1825,9 & 40,0 & 211,0 & 5,8 & 0,18 & 45,9 & 0,12 \\
\hline Приморский край & 643,9 & 33,0 & 229,5 & 5,0 & 0,16 & 54,3 & 0,12 \\
\hline
\end{tabular}

Примечание. ИВ - инфицированность ВИЧ на 100000 населения; АД - аборты добровольные на 100 родов; ИА - индекс алкоголизации; КР - коэффициент разводимости; СС - смертность от самоубийств на 1000 населения; ТП - тяжкая преступность на 10000 населения; СУ - смертность от убийств на 1000 населения.

Таблица 3

Выраженность показателей социально-психологической напряженности населения модельных регионов РФ

\begin{tabular}{|c|c|c|c|c|c|}
\hline \multirow{2}{*}{ Регион } & \multicolumn{5}{|c|}{ Показатели } \\
\hline & $\Phi$ & $\mathrm{P}$ & $\mathrm{O}$ & $\bar{A}$ & $\Pi$ \\
\hline Республика Крым & 5,74 & 5,98 & 5,21 & 0,44 & 0,68 \\
\hline Краснодарский край & 4,93 & 5,05 & 5,08 & 0,42 & 0,7 \\
\hline Республика Адыгея & 4,35 & 4,7 & 4,5 & 0,33 & 0,72 \\
\hline Ростовская область & 4,52 & 4,75 & 5,59 & 0,37 & 0,84 \\
\hline Астраханская область & 4,25 & 4,24 & 4,36 & 0,31 & 0,81 \\
\hline Волгоградская область & 4,1 & 4,3 & 4,7 & 0,3 & 0,7 \\
\hline Саратовская область & 4,46 & 4,36 & 4,45 & 0,48 & 0,8 \\
\hline Воронежская область & 4,49 & 4,92 & 5,05 & 0,41 & 0,78 \\
\hline Республика Карелия & 4,7 & 4,4 & 4,88 & 0,5 & 0,66 \\
\hline Архангельская область & 4,4 & 4,12 & 4,4 & 0,41 & 0,73 \\
\hline Ленинградская область & 5,6 & 5,03 & 5,58 & 0,65 & 0,74 \\
\hline Иркугская область & 4 & 4,25 & 4,61 & 0,43 & 0,76 \\
\hline Приморский край & 3,64 & 3,88 & 4,23 & 0,5 & 0,81 \\
\hline
\end{tabular}

Примечание. Ф - фрустрация; Р - раздражение; О - обида; А - агрессия; П - помощь. 


\section{СОЦИОЛОГИЯ И СОЦИАЛЬНЫЕ ТЕХНОЛОГИИ}

правленности и выраженности связей исследуемых показателей рассчитывался коэффициент корреляции $r$ - Спирмена. Формирование базы данных первичной информации и статистическая обработка результатов исследования производились в программах MS Excel 2007 (12.0.6611.1000) (Microsoft), Statistica 6.0 (StatSoft).

Обобщение полученных результатов обеспечило выявление ряда комплексных взаимосвязей исследуемых показателей.

Прежде всего были проанализированы связи основных показателей социальной и криминальной напряженности с географическими координатами среды жизнедеятельности населения России (рис. 1).
Представленные данные свидетельствуют о наличии выраженных положительных связей отдельных показателей социальной напряженности (аборты и суицид) с градусами северной широты места жительства $(\mathrm{p}<0,05)$. В то же время анализируемые показатели криминальной напряженности (уровень тяжких преступлений и смертность от убийств), в большей степени прямо, статистически значимо $(\mathrm{p}<0,01)$ связаны с восточной долготой места жительства населения.

Физические характеристики среды обитания также имеют выраженную связь с основными показателями социальной и криминальной напряженности у населения РФ (рис. 2).

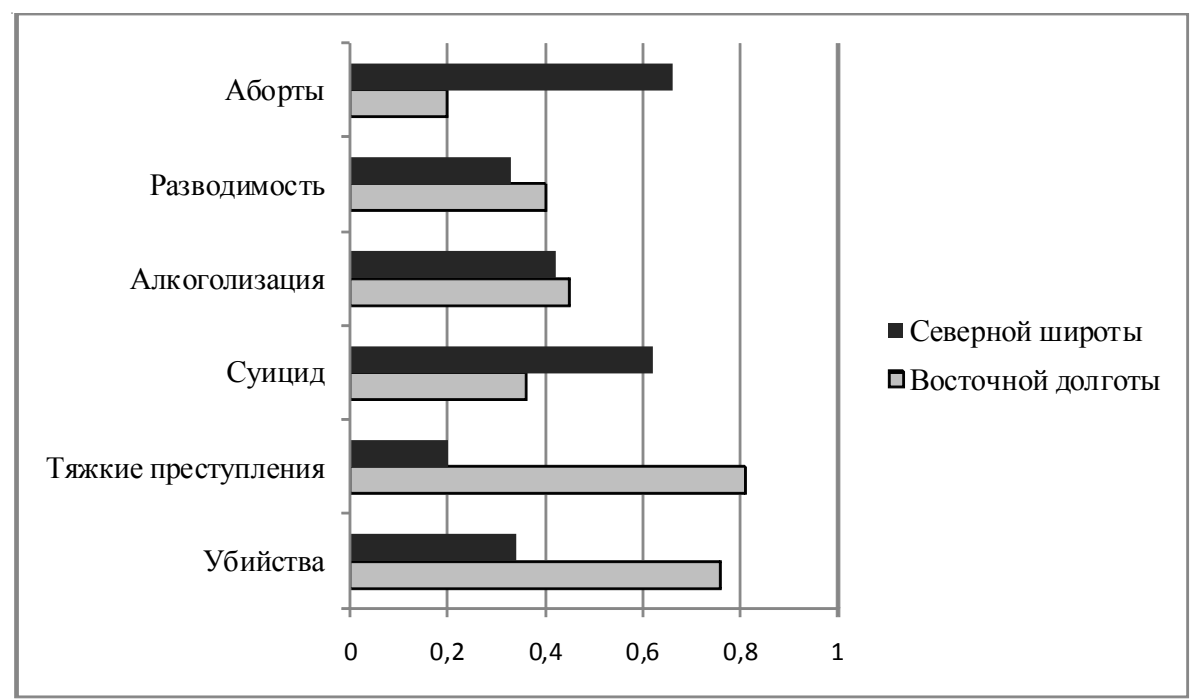

Рис. 1. Корреляционные связи географических координат места жительства с показателями социальной и криминальной напряженности социума

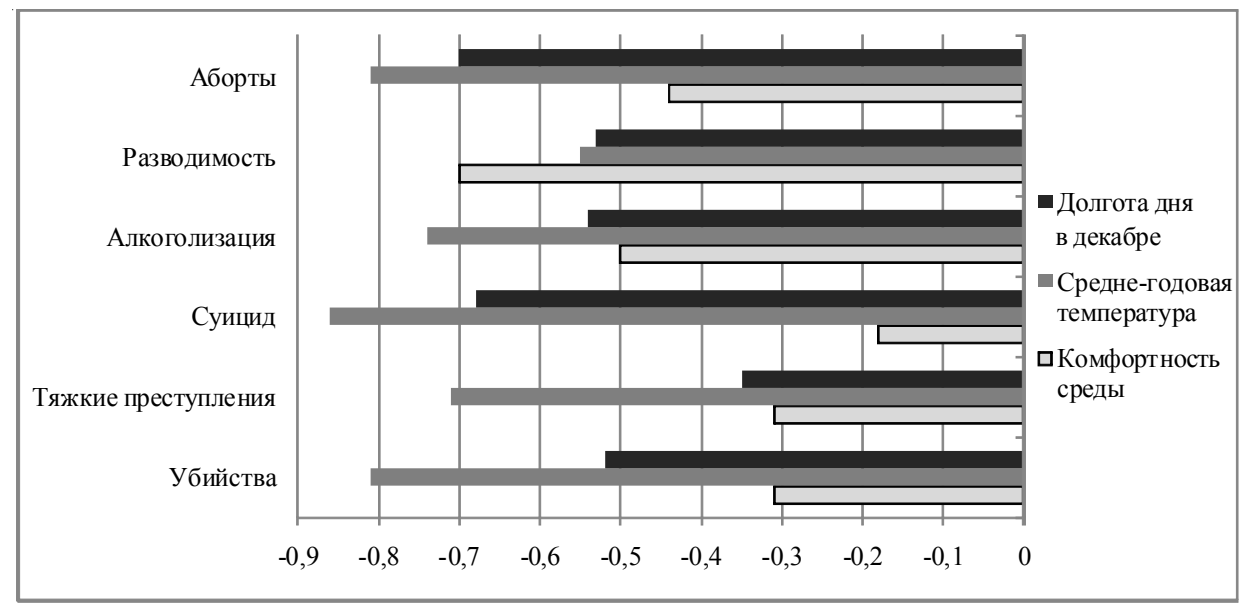

Рис. 2. Корреляционные связи физико-географических характеристик среды с показателями социальной и криминальной напряженности социума 
А.Б. Мулик. Региональная специфика проявления социальной и криминальной напряженности

В представленных данных, прежде всего, обращает на себя внимание статистически значимая отрицательная связь среднегодовой температуры воздуха со всеми анализируемыми показателями социальной и криминальной напряженности социума ( $\mathrm{p}<0,05$ для уровня разводов и $\mathrm{p}<0,01$ для остальных показателей). Кроме этого, среди показателей социальной напряженности, уровень добровольных абортов и суицида значимо ( $\mathrm{p}<0,01)$ отрицательно связаны с долготой дня в декабре, а уровень разводов - с комфортностью среды жизнедеятельности $(\mathrm{p}<0,01)$.

Предпринятый анализ связей показателей социальной и криминальной напряженности с показателями социально-психологического состояния представителей населения модельных территорий Российской Федерации выявил некоторые характерные закономерности их проявления (рис. 3,4 ).

Во-первых, склонность к агрессивному поведению прямо коррелирует со всеми анализируемыми показателями социальной и криминальной напряженности, не достигая однако в большинстве случаев статистически значимой связи. Исключение составляет статистически значимая связь агрессивности населения с ВИЧ инфицированностью и уровнем суицида в социуме $(\mathrm{p}<0,05)$. Склонность к оказанию помощи характеризуется незначительной отрицательной корреляцией с большинством показателей социальной и криминальной напряженности социума.

Во-вторых, фрустрация, раздражение и обида в комплексе имеют устойчивую отрицательную связь со всеми показателями со-

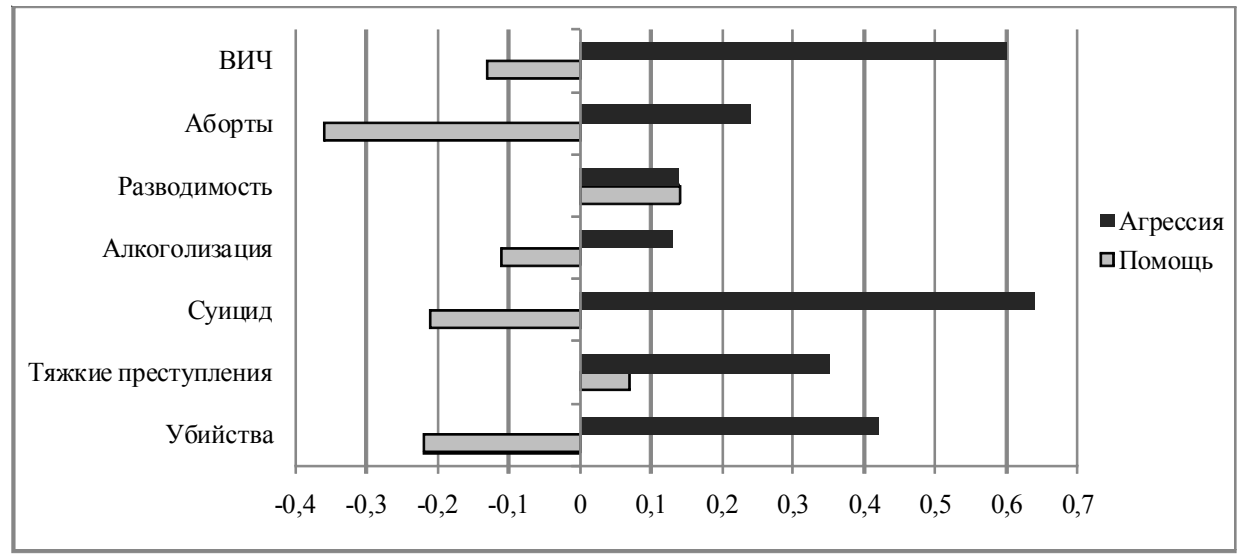

Рис. 3. Корреляционные связи показателей социальной и криминальной напряженности социума с некоторыми показателями социально-психологического статуса населения

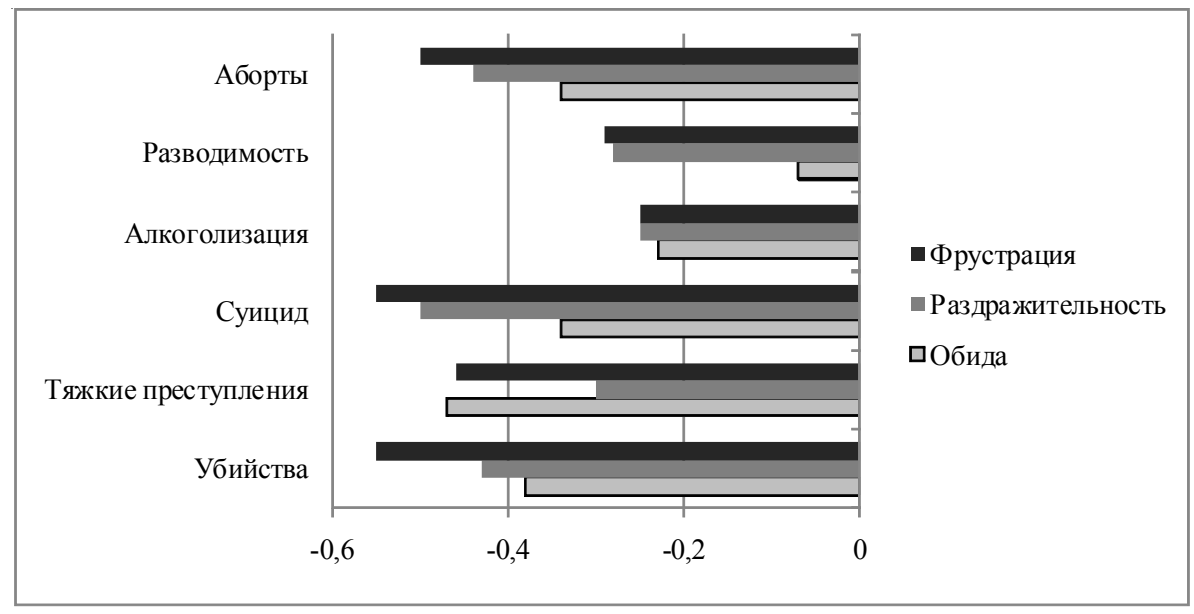

Рис. 4. Корреляционные связи показателей социальной и криминальной напряженности социума с некоторыми показателями психологического состояния населения 
циальной и криминальной напряженности. При этом выраженность фрустрации отрицательно, статистически значимо $(\mathrm{p}<0,05)$ коррелирует только с уровнем суицида и уровнем убийств в социуме.

Результаты, полученные по комплексу выполненных исследований, свидетельствуют о наличии системных связей уровня социальной и криминальной напряженности с физико-географическими характеристиками территорий проживания населения. Следует констатировать возможноевлияние на становление социального статуса популяционного сообщества северной широты и восточной долготы места жительства, уровня среднегодовой температуры и долготы дня в зимнее время года. Недостаточная комфортность территории проживания человека, как производное от совокупности природных и антропогенных компонентов среды, способна вносить существенный вклад в формирование социальной и криминальной напряженности социума.

Показатели уровня социальной и криминальной напряженности, в свою очередь, находятся в тесной связи с выраженностью некоторых психологических показателей асоциального и просоциального поведения населения Российской Федерации. Это дополнительно подтверждает системность популяционного формирования социального и психологического статуса жителей регионов России.

Таким образом, системный учет региональных факторов среды жизнедеятельности человека может обеспечить прогнозирование специфики и выраженности риска формирования социальной и криминальной напряженности в социуме.

\section{ПРИМЕЧАНИЕ}

${ }^{1}$ Работа выполнена при финансовой поддержке РФФИ и Администрации Волгоградской области в рамках реализации Проекта № 17-16-34019ОГН-Р ВОЛ-А «Поведенческие риски инфицирования ВИЧ и парентеральными гепатитами в организованных контингентах учащейся молодежи».

\section{СПИСОК ЛИТЕРАТУРЫ}

1. Бойко, В. В. Психоэнергетика / В. В. Бойко. СПб : Питер, 2008. - 416 с.
2. Вернадский, В. И. Биосфера и ноосфера / В. И. Вернадский. - М. : Айрис-пресс, 2004. $576 \mathrm{c}$.

3. Галяутдинова, С. И. К вопросу о влиянии зон биологического дискомфорта на человека / С. И. Галяутдинова, Л. Н. Белан, Р. Б. Гумерова // Вестник Башкирского университета. 2012. - Т. 17, № 3. - С. 1403-1406.

4. Кряжимский, Ф. В. Надорганизменные системы в экологии человека /Ф. В. Кряжимский, В. Н. Большаков // Экология. -2005 . - №3. - С. 163-170.

5. Майорова, Е. В. Природная среда: понятие, структура, основные подходы (теоретико-методологический анализ) / Е. В. Майорова, Т. А. Смирнов, Р. П. Цырульник // Вестник Московского городского педагогического университета. Серия Естественные науки. - 2014. - № 4 (16). - С. 87-95.

6. Мулик, А. Б. Системные механизмы популяционного формирования поведенческой и социальной активности человека : монография / А. Б. Мулик. -М. : РУСАЙНС, 2017.-152 c.

7. Пат. Российская Федерация 2623302. Способ оценки склонности к просоциальному-асоциальному поведению / Мулик А. Б., Безрукова А. Н., Тимофеева Т. С., Шатыр Ю. А., Мулик И. Г., Антонов Г. В. - Заявл. 10.12.2015 ; опубл. 23.06.2017, Бюл. № 18.

8. Природа. Экология // Национальный атлас России. В 4 т., Т. 2. / гл. ред. В. М. Котляков.-М. : Роскартография, 2007. - Режим доступа: http://национальныйатлас.pф/cd2/territory.html. - Загл. с экрана.

9. Черемушникова, И. И. Микроэлементные аспекты агрессивных тенденций в поведении / И. И. Черемушникова // Микроэлементы в медицине. -2012 . - Т. 13, № 4. - С. 24-31.

10. Черешнев, В. А.Человек и три окружающие его среды / В. А. Черешнев, А. Г. Гамбурцев, Т. К. Бреус // Вестник Российской академии наук. 2007. - T. 77, № 7. - С. 618-627.

11. Jian, Y. Effect Modification by Environmental Quality on the Association between Heatwaves and Mortality in Alabama, United States / Y. Jian, C. Y. H. Wu, J. M. Gohlke// International Journal of Environmental Research and Public Health. - 2017. Vol. 28, № 14 (10). - DOI: 10.3390/ijerph14101143.

\section{REFERENCES}

1. Boyko V.V. Psikhoenergetika [PsychoEnergetics]. Saint Petersburg, Piter Publ., 2008. 416 p.

2. Vernadskiy V.I. Biosfera $i$ noosfera [The Biosphere and the Noosphere]. Moscow, Ayrispress, $2004.576 \mathrm{p}$.

3. Galyautdinova S.I., Belan L.N., Gumerova R.B. $\mathrm{K}$ voprosu o vliyanii zon biologicheskogo diskomforta 
na cheloveka [On the Impact of Biological Discomfort Zones on Humans]. Vestnik Bashkirskogo universiteta [Bulletin of Bashkir State University], 2012, vol. 17, no. 3, pp. 1403-1406.

4. Kryazhimskiy F.V., Bolshakov V.N. Nadorganizmennye sistemy v ekologii cheloveka [Supra-Organism Systems in Human Ecology]. Ekologiya [Ecology], 2005, no. 3, pp. 163-170.

5. Mayorova E.V., Smirnov T.A., Tsyrulnik R.P. Prirodnaya sreda: ponyatie, struktura, osnovnye podkhody (teoretiko-metodologicheskiy analiz) [Natural Environment: Concept, Structure, Main Approaches (Theoretical and Methodological Analysis)]. Vestnik Moskovskogo gorodskogo pedagogicheskogo universiteta, Seriya Estestvennye nauki [Bulletin of the Moscow City Pedagogical University. Series of Natural Sciences], 2014, no. 4(16), pp. 87-95.

6. Mulik A.B. Sistemnye mekhanizmy populyatsionnogo formirovaniya povedencheskoy $i$ sotsialnoy aktivnosti cheloveka: monografiya [Systemic Mechanisms of Population Formation of Human Behavioral and Social Activity: Monograph]. Moscow, Rusayns Publ., 2017. 152 p.

7. Mulik A.B., Bezrukova A.N., Timofeeva T.S., Shatyr Yu.A., Mulik I.G., Antonov G.V. Patent. Rossiyskaya Federatsiya 2623302. Sposob otsenki sklonnosti $k$ prosotsialnomu-asotsialnomu povedeniyu [Patent of the Russian Federation 2623302. A Way of Estimation of Propensity to ProsocialAsocial Behavior]. Publ. June 23, 2017. Bul. No. 18. (in Russian).

8. Kotlyakov V.M., ed. Priroda. Ekologiya [Nature. Ecology]. Natsionalnyy atlas Rossii. V $4 t$. T. 2 [National Atlas of Russia. In 4 vols. Vol. 2]. Moscow, Roskartografiya Publ., 2007. URL: http://национальныйатлас.pф/cd2/territory.html.

9. Cheremushnikova I.I. Mikroelementnye aspekty agressivnykh tendentsiy $\mathrm{v}$ povedenii [Microelement Aspects of Aggressive Tendencies in Behavior]. Mikroelementy $v$ meditsine [Microelements in Medicine], 2012, vol. 13, no. 4, pp. 24-31.

10. Chereshnev V. A., Gamburtsev A. G., Breus T.K. Chelovek i tri okruzhayushchie ego sredy [Man and the Three Environments around Him]. Vestnik Rossiyskoy akademii nauk [Bulletin of the Russian Academy of Sciences], 2007, vol. 77, no. 7, pp. 618-627.

11. Jian Y., Wu C.Y.H., Gohlke J.M. Effect Modification by Environmental Quality on the Association between Heatwaves and Mortality in Alabama. United States International Journal of Environmental Research and Public Health, 2017, vol. 28 , no. 14 (10). DOI: 10.3390/ijerph14101143.

\section{Information about the Author}

Aleksandr B. Mulik, Doctor of Sciences (Biology), Professor, Chief Researcher, Director of Research and Education Center for Physiology and Homeostasis, Volgograd State University, Prosp. Universitetsky, 100, 400062 Volgograd, Russian Federation, mulikab@mail.ru, mulik@volsu.ru.

\section{Информация об авторе}

Александр Борисович Мулик, доктор биологических наук, профессор, главный научный сотрудник, руководитель научно-образовательного центра физиологии гомеостаза, Волгоградский государственный университет, просп. Университетский, 100, 400062 г. Волгоград, Российская Федерация, mulikab@mail.ru, mulik@volsu.ru. 